\title{
Multicenter study on the prognosis associated with respiratory support for children with acute hypoxic respiratory failure
}

\author{
FEI GUO*, LIN HAO*, QING ZHEN, MIN DIAO and CHONGLIN ZHANG \\ Department of Respiratory Medicine, Xuzhou Children's Hospital, Xuzhou, Jiangsu 221002, P.R. China \\ Received July 25, 2016; Accepted September 28, 2016
}

DOI: $10.3892 /$ etm.2016.3772

\begin{abstract}
The objective of the present study was to explore the factors influencing the outcomes related to respiratory support of children with acute hypoxic respiratory failure (AHRF) in 30 hospitals. This was a non-controlled prospective and collaborative multicenter clinical study conducted from June, 2010 to May, 2011 (each hospital for 12 consecutive months). Children aged from 29 days to 6 years and who met the diagnostic standards of AHRF were enrolled as subjects for the study. After patients were enrolled, general parameters including disease diagnosis, treatment and prognosis were recorded. Then we analyzed the differences in prognosis and respiratory therapy of patients with AHRF. During the study period, 13,906 cases of AHRF were admitted among the 30 hospitals, accounting for $75.3 \%$ of the total number of patients with AHRF. The proportion in different hospitals ranged from 16 to $98 \%$. A total of 492 children with hypoxic respiratory failure were admitted among the 30 hospitals. The prevalence rate was $3.54 \%$, and the incidence of AHRF in each hospital was $4.54 \%$. Tidal volume and respiratory support treatment were compared with the results from a 2006 study, and the differences were statistically significant in positive end-expiratory pressure ( 5 vs. $4, \mathrm{P}=0.018$ ), fraction of inspire $\mathrm{O}_{2}(0.5$ vs. $0.4, \mathrm{P}<0.001)$, pressure of artery $\mathrm{O}_{2}$ (70 vs. $\left.60 \mathrm{mmHg}, \mathrm{P}<0.001\right)$ and peak inspiratory pressure ( 20 vs. $24 \mathrm{~cm} \mathrm{H} \mathrm{H}_{2} \mathrm{O}, \mathrm{P}<0.001$ ). In conclusion, academic background and the level of regional economic development are factors which influence the prognosis of children with AHRF. On the basis of unapparent differences between academic background and the level of regional economic development, there is a substantial difference in the prognosis from different forms of respiratory support management for AHRF. Therefore, it is essential to develop respiratory
\end{abstract}

Correspondence to: Dr Qing Zhen, Department of Respiratory Medicine, Xuzhou Children's Hospital, 18 Sudibei Road, Xuzhou, Jiangsu 221002, P.R. China

E-mail: zhangchonglin3611@163.com

${ }^{*}$ Contributed equally

Key words: children, critical disease, respiratory therapy, low tidal volume therapy support and the level of critical management of pediatric intensive care units.

\section{Introduction}

Acute hypoxic respiratory failure (AHRF) in children is a common and critical illness that occurs in the pediatric intensive care unit (PICU). It mostly progresses to acute respiratory distress syndrome (ARDS) and is a common cause of death in the PICU. In PICUs of China, the occurrence rate of AHRF is $4 \%$, and the mortality rate is $41.8 \%$. The occurrence rate of ARDS is $1.44-2.7 \%$ and the mortality rate is $46.4-60.3 \%(1,2)$. In PICUs in other countries, the occurrence rate of ARDS is $0.7-4.2 \%$ and the mortality rate is $20-75 \%$ (3-6). Owing to the gradual wide application of respiratory support and intensive care technologies, a large number of fatal cases have survived, with a mortality rate of $<1.6 \%$ (7). Non-invasive ventilation via mechanical ventilation improves gas exchange and establishes a good environment for reducing the occurrence of low blood oxygen in patients with acute respiratory failure (8). However, the relatively complex multiple-organ dysfunctions caused by various unexpected, rare, and complicated respiratory infections, and large differences among nationwide developmental levels of respiratory support technologies caused by unequal levels of economic and medical development, have limited the spread of the use of respiratory support and intensive care technologies in children with AHRF (9).

After the cooperative studies from our center on children with ARDS and AHFR in 2004 and from 2005 to 2006, the clinical epidemiological characteristics of ARDS and AHRF in domestic PICUs have changed (10). Therefore, assisted research on respiratory support for children with AHRF was conducted in 2010, and children with AHRF among 30 hospitals across various regions of China were selected to perform a prospective multicenter epidemiological study. The prognosis associated with treatment with respiratory support in different regions and different PICUs of hospitals with different mechanical ventilation strategies were analyzed and compared in this study.

\section{Materials and methods}

Research design. Before beginning the study, the person in charge and PICU-related hospital staff of each cooperation unit participated in professional training. Patient data were recorded and counted by specially designated personnel of 
each cooperation unit. PICU basic data forms were completed by those responsible and transferred through electronic mail, telephone, physical mail, or through a dedicated website established by the cooperation groups to the coordination center (Department of Respiratory and Critical Care Laboratory, Department of Pediatric Hospital, Fudan University, Shanghai, China), and were then entered in the database of the coordination center for analysis. Since most of the collaboration units participated in the collaborative study on AHRF in 2006, they were relatively familiar with the research data. Therefore, they mainly solved problems that occurred in everyday contact and monthly data collection process, as well as stage summary.

This was a descriptive and prospective multicenter clinical epidemiological study. The study period was from 1 June, 2010 to 31 May, 2011, lasting 12 consecutive months. PICUs of 30 hospitals in China were enrolled including the original national children AHRF collaboration group. Sixteen of these were university-affiliated hospitals and the remaining 14 were non-affiliated. Simultaneously, in accordance with the per capita gross national product (GNP) rankings and the rankings of per capita income of urban residents of the provinces and cities that each unit belonged to, the first 15 hospitals were ranked as hospitals in economically developed regions, while the remaining 15 were in less developed regions.

Case selection and data collection. Children aged from 29 days to 6 years who were admitted to the PICU and in accordance with AHRF diagnostic criteria were included in the current study. To reduce the selection bias of the data of children with critical illnesses admitted to different hospitals and in different periods of each hospital, and to ensure the uniformity of admission standards, the pediatric critical illness scoring system, as well as American guidelines for admission (11) and discharge policies for PICUs (12) were used for the research group as the criteria for critically ill patients.

Diagnostic criteria. Diagnostic criteria for respiratory failure were (13): Acute onset ( $\leq 2$ weeks); pressure of artery $\mathrm{O}_{2}\left(\mathrm{PaO}_{2}\right) \leq 50 \mathrm{mmHg}$ or $\mathrm{PaO}_{2} /$ fraction of inspired $\mathrm{O}_{2}\left(\mathrm{FiO}_{2}\right) \leq 50 \mathrm{mmHg}$; mechanical ventilation via tracheal intubation $\left[\mathrm{FiO}_{2} \geq 30 \%\right.$, positive end-expiratory pressure $(\mathrm{PEEP}) \geq 2 \mathrm{~cm} \mathrm{H} \mathrm{H}_{2} \mathrm{O}$ ] can maintain $\mathrm{PaO}_{2} \geq 60 \mathrm{mmHg}$, or percutaneous pulse oxygen saturation $\left(\mathrm{SpO}_{2}\right) \geq 90 \%$ for $>12 \mathrm{~h}$, and respiratory failure exists after $12 \mathrm{~h}$ of ventilation; $\mathrm{PaO}_{2} / \mathrm{FiO}_{2} \leq 250 \mathrm{mmHg}$; at the same time, acute ventilatory dysfunction induced respiratory failure caused by the central nervous system or neuromuscular diseases as well as heart diseases should be excluded.

For the diagnosis of acute lung injury (ALI)/ARDS, the criteria formulated by the American-European Consensus Conference (AECC) in 1994 was used (14): i) Acute onset ( $\leq 2$ weeks); ii) $\mathrm{PaO}_{2} / \mathrm{FiO}_{2} \leq 300 \mathrm{mmHg}$ (ALI) or $\mathrm{PaO}_{2} / \mathrm{FiO}_{2}$ $\leq 200 \mathrm{mmHg}$ (ARDS); iii) exudation shadows in both lungs are shown on chest radiograph; and iv) no clinical evidence of left atrial hypertension (pulmonary arterial wedge pressure $\leq 18 \mathrm{mmHg}$ or diagnosis by portable color Doppler ultrasound).

Statistical analysis. Patient data were entered in the computer to establish a Microsoft Access database. SPSS 13.0 statistical software (SPSS, Inc., Chicago, IL, USA) was used for statistical analysis. The continuous variables with normal distribution in measurement data were presented as mean $\pm \mathrm{SD}$, and mean values were compared by one-way analysis of variance (ANOVA). Partial distributors were expressed as medians and quartiles (P25 and P75), and the mean values were compared using the Wilcoxon test. Non-continuous variables or categorical data, which included ratios, were compared with the Chi-square test.

\section{Results}

General conditions in the PICU. During the 12-month study period, 18,648 cases were admitted among the 30 PICUs, and 13,906 cases were critical $(75.3 \%, 13,906 / 18,468)$, including 8,149 cases with pediatric critical illness scores $\leq 90(58.6 \%$, $8,179 / 13,906)$ and 5,757 cases with scores $>90$ but were in accordance with the criteria of American discharge policies for PICUs $(41.4 \%, 5,757 / 13,906)$. The median value of the proportion of critical patients was $77.6 \%$ (22.6-88.7\%) (Fig. 1). The number of dead patients with critical illness was 1,436 for the whole year (including 583 cases that died within 3 days after discharge from the hospital), the annual average mortality rate from PICUs was $10.3 \%(1,436 / 13,906)$, the number of patients who gave-up treatment and discharged from the hospital was 1,826 including those who died within three days after discharging automatically from the hospital, and the rate of abandonment from the study was $13.1 \%$.

A total of 560 cases from 30 PICUs conforming to the diagnostic criteria of AHRF were enrolled and 68 cases were eventually removed. Therefore, a total of 492 cases with AHRF were included. All the cases were treated with mechanical ventilation via tracheal intubation. The total prevalence rate of AHRF was 3.54\% $(492 / 13,906)$, the median value of the prevalence rate in each PICU was $4.54 \%$, with the lowest value of $1.07 \%$ and the highest value of $20.1 \%$ (Fig. 2). The total mortality rate of patients with AHRF was $26.6 \%$ (131/492), the mortality rates of each unit were unequal and differed greatly, and the median value was $31.7 \%$. Among 492 cases with AHRF, 286 were female $(58.1 \%)$, and the ratio of males-to-females was 1.4:1. The average age of all children was 1.3 years, and the median age was 0.8 years $(0.3-2.4)$. Children younger than 1 year accounted for $57.1 \%$ (42.9 cases), and others younger than 2 years accounted for $66.7 \%$ (328 cases) (Table I).

Comparisons of prevalence rates, mortality rates, and disease burden of AHRF in hospitals of different areas and different grades. The per capita gross domestic product (GDP) of provinces and cities of the 15 hospitals in economically developed areas was 56,152 yuan, the per capita disposable income of urban residents was 22,346 yuan, and the per capita income of rural residents was 8,674 yuan. The per capita GDP of residents in economically less developed areas was 22,330 yuan, which was half of the average value of the economically developed areas; the per capita disposable income of urban residents was 15,689 yuan, which was $2 / 3$ of the average of developed areas; and there were 6 less university-affiliated hospitals in less developed areas than in developed areas in this study.

Regarding economic burdens, the ratio of average cost associated with AHRF in hospital and the annual income of urban 


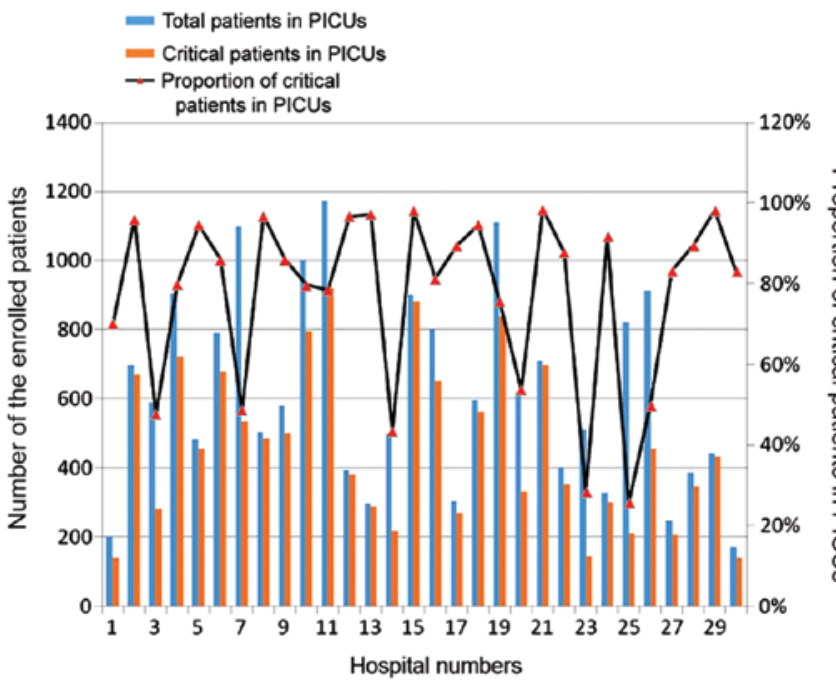

Figure 1. The proportions of critical patients in the PICUs of 30 hospitals. The blue histogram is the total number of included patients in PICUs; the red histogram is the number of critical patients in PICUs; and the line graph is the proportion of critical patients in different PICUs. The ratio between critical cases in the 30 hospitals and cases in each PICU were markedly different. The median value of critical cases in different PICUs was $77.6 \%$ (22.6-88.7\%). PICUs, pediatric intensive care units.

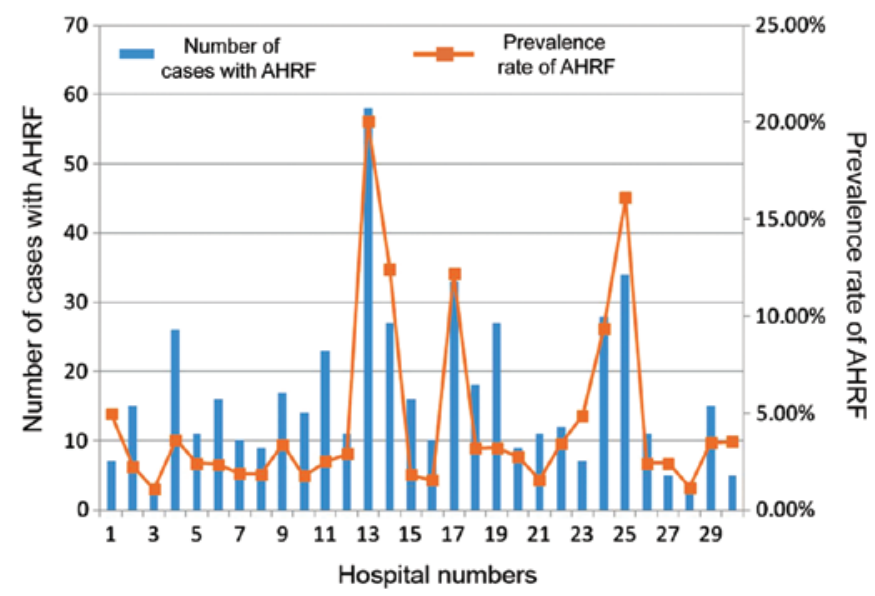

Figure 2. Comparisons of the prevalence rates of critical cases with AHRF in PICUs of the 30 hospitals. Histograms are the number of cases with AHRF in each unit, and line graphs are the prevalence rate of patients with AHRF. The prevalence rate of AHRF markedly differed in different units, and except for the 13th unit, the differences among the prevalence rates of the remaining units were relatively smaller. AHRF, acute hypoxic respiratory failure; PICUs, pediatric intensive care units.

residents in developed areas was $1.05(23,687 / 22,364)$, and was 2.6 when it comes to the rural residents $(23,687 / 8,674)$, while the ratio in less developed areas was $1.50(23,461 / 15,689)$ of urban residents and $4.97(23,461 / 4,723)$ of rural residents (Table II). Therefore, according to the incomes of patients' family in different areas, although the critical degrees of admitted patients in developed areas were higher, the total medical costs between them differed insignificantly $(\mathrm{P}>0.05)$. By contrast, the disease burdens of patients in developed areas were lighter.

Our analysis revealed the incidence of AHRF and ARDS in hospitals in less developed areas was higher than that in developed areas, which was also the case for the mortality rates, albeit the
Table I. The basic conditions and respiratory parameters of included patients with AHRF.

\begin{tabular}{|c|c|}
\hline Parameters & Data \\
\hline Age (years) & $0.8(0.3-2.4)$ \\
\hline$<1$ year & $281(57.1)$ \\
\hline$\geq 1$ year & $211(42.9)$ \\
\hline$<2$ years & $328(66.7)$ \\
\hline$\geq 2$ years & $164(33.3)$ \\
\hline Female & $286(58.1)$ \\
\hline PEEP, $\mathrm{cm} \mathrm{H}_{2} \mathrm{O}$ & $5(36)$ \\
\hline $\begin{array}{l}\mathrm{PIP}, \mathrm{cm} \mathrm{H} \mathrm{H}_{2} \mathrm{O} \\
\mathrm{MAP}, \mathrm{cm} \mathrm{H}_{2} \mathrm{O}\end{array}$ & $20(16-24)$ \\
\hline $\mathrm{MAP}, \mathrm{cm} \mathrm{H}_{2} \mathrm{O}$ & $12(10-14)$ \\
\hline $\mathrm{PaO}_{2} / \mathrm{FiO}_{2}$ & $138(106-192)$ \\
\hline OI & $8.4(106-187)$ \\
\hline
\end{tabular}

Data are presented as median (P25-P75) or the number of cases in percentage. AHRF, acute hypoxic respiratory failure; PEEP, positive end-expiratory pressure; PIP, peak inspiratory pressure; MAP, mean airway pressure; $\mathrm{PaO}_{2}$, pressure of artery $\mathrm{O}_{2} ; \mathrm{FiO}_{2}$, fraction of inspire $\mathrm{O}_{2}$; OI, oxygenation index.

mortality rate was not statistically significant $(\mathrm{P}>0.05)$. Similarly, the incidence of AHRF and ARDS in the non-university-affiliated hospitals was lower than that in university-affiliated hospitals, while the mortality rates were higher than those of the latter, with no statistically significant differences $(\mathrm{P}>0.05)$. The rate of giving-up in university-affiliated hospitals was $16.9 \%$, which was lower than that of non-university-affiliated hospitals which was $21.4 \%$, and there was no statistically significant difference $(\mathrm{P}>0.05)$ (Table III).

Comparisons of respiratory support therapy in different hospitals and regions. The proportion of use of mechanical ventilation for critical cases in developed areas was $26.5 \%$, which was $<30.5 \%$ in the less developed areas, and the proportion of use of mechanical ventilation in university-affiliated hospitals was $38.4 \%$, which was significantly higher than that of $18.7 \%$ in non-affiliated hospitals (Table IV). From the comparison of specific respiratory parameters, it was found that LIS of patients admitted to university-affiliated hospitals and hospitals in developed areas was higher and the ratio of $\mathrm{PaO}_{2} / \mathrm{FiO}_{2}$ was relatively lower. In addition, oxygenation index of patients in university-affiliated hospitals was higher than that of non-affiliated hospitals, which indicated the critical degree was higher. Comparing specific respiratory parameters, PEEP, peak inspiratory pressure (PIP), and MAP, which were measured in patients of university-affiliated hospitals, were higher than those in non-affiliated hospitals, but the differences were not statistically significant $(\mathrm{P}>0.05)$. Similarly, expiratory tidal volume (Vte) and mean airway pressure (MAP) of hospitals in the developed areas were slightly higher than those of hospitals in less developed areas, and the differences were not statistically significant. The trends of PEEP and PIP were in contrast with those in university-affiliated hospitals and non-university-affiliated hospitals (Tables V and VI). 
Table II. The per capita GDP and per capita income of residents in hospitals of different areas and different grades.

\begin{tabular}{|c|c|c|c|}
\hline Hospitals & $\begin{array}{c}\text { Per capita } \\
\text { GDP (Yuan) }\end{array}$ & $\begin{array}{l}\text { Per capita income of } \\
\text { rural residents (Yuan) }\end{array}$ & $\begin{array}{l}\text { Per capita income of } \\
\text { urban residents (Yuan) }\end{array}$ \\
\hline $\begin{array}{l}\text { Hospitals in } \\
\text { developed areas }\end{array}$ & 6,152 & 8,674 & 22,364 \\
\hline $\begin{array}{l}\text { Hospitals in less } \\
\text { developed areas }\end{array}$ & 22,330 & 4,723 & 15,689 \\
\hline $\begin{array}{l}\text { University-affiliated } \\
\text { hospitals }\end{array}$ & 35,189 & 6,020 & 15,900 \\
\hline $\begin{array}{l}\text { Non-affiliated } \\
\text { hospitals }\end{array}$ & 20,561 & 3,678 & 15,670 \\
\hline AHRF costs & 23,687 & 23,461 & 25,123 \\
\hline
\end{tabular}

GDP, gross domestic product; AHRF, acute hypoxic respiratory failure.

Table III. Comparison of AHRF and ARDS in hospitals of different areas and different grades.

\begin{tabular}{lcccc}
\hline Rates & $\begin{array}{c}\text { Developed } \\
\text { areas }\end{array}$ & $\begin{array}{c}\text { Less developed } \\
\text { areas }\end{array}$ & $\begin{array}{c}\text { University-affiliated } \\
\text { hospitals }\end{array}$ & $\begin{array}{c}\text { Non-affiliated } \\
\text { hospitals }\end{array}$ \\
\hline Occurrence rate of AHRF, \% (n) & $3.1(188)$ & $3.8(304)$ & $3.2(227)$ & $3.9(265)$ \\
Occurrence rate of ARDS, \% (n) & $1.9(112)$ & $3.4(272)$ & $2.4(169)$ & $3.3(225)$ \\
Mortality rate of AHRF, \% (n) & $28.4(42)$ & $32.6(99)$ & $23.8(54)^{\mathrm{a}}$ & $29.1(77)$ \\
Mortality rate of ARDS, \% (n) & $25.6(29)$ & $32.0(87)$ & $19.8(45)^{\mathrm{b}}$ & $30.7(69)$ \\
Abandonment rate of AHRF, \% (n) & $16.9(24)$ & $21.4(65)$ & $24.9(66)$ \\
\hline
\end{tabular}

Comparing between two groups, $\chi^{2}=1.74,{ }^{\text {a }}>0.05 ; \chi^{2}=1.81,{ }^{b} \mathrm{P}>0.05$. AHRF, acute hypoxic respiratory failure; ARDS, acute respiratory distress syndrome.

Table IV. Comparisons of total PICU data in different regions and different hospitals.

\begin{tabular}{|c|c|c|c|c|}
\hline Data & $\begin{array}{l}\text { Developed } \\
\text { areas }\end{array}$ & $\begin{array}{c}\text { Less developed } \\
\text { areas }\end{array}$ & $\begin{array}{l}\text { University-affiliated } \\
\text { hospitals }\end{array}$ & $\begin{array}{l}\text { Non-affiliated } \\
\text { hospitals }\end{array}$ \\
\hline Critical cases, \% (n) & $82.3(5,917)$ & $75.6(7,989)$ & $88.3(7,115)$ & $72.5(6,791)$ \\
\hline Mortality rate, \% (n) & $9.5(543)$ & $10.1(893)$ & $10.3(734)$ & $9.1(702)$ \\
\hline Rate of abandonment, \% (n) & $12.2(581)$ & $16.8(1,245)$ & $11.5(786)$ & $17.2(1,040)$ \\
\hline Mechanical ventilation, $\%$ (n) & $26.5(1,568)$ & $30.5(2,436)$ & $38.4(2,732)$ & $18.7(1,272)$ \\
\hline
\end{tabular}

PICU, pediatric intensive care unit.

\section{Discussion}

We found that the proportions of critical cases/total AHRF cases and the mortality of AHRF were markedly different among various hospitals, considering hospitals with high medical condition may have more critical cases admitted in PICU and the gaps of medical condition in these hospitals were small (15). In subsequent studies, to eliminate bias caused by the differences of overall medical level between different units, units with greater proportions of critical cases, higher proportions of use of mechanical ventilation, and more enrolled cases were selected as cooperative units (16). However, a comparison of the rates of abandonment, mortality rates, and total medical costs of AHRF of different hospitals and different areas, the results showed that there were no statistically significant differences between them in the developed and less developed areas. Additionally, the total medical expenses were not significantly different. With the development of the academic exchange, multicenter clinical studies, and economic development, the gaps between the medical levels of large hospitals in China are becoming increasingly smaller (17). The results showed that in patients between 29 days and 6 years, the occurrence rate of AHRF in domestic PICUs was equal to the level from 2006. However, there was a significant decrease in the mortality rates of the patients, in AHRF, and ARDS, suggesting that respiratory support technology has gradually improved. 
Table V. Comparison of mechanical ventilation parameters on the first, third and seventh day after admission of patients to hospitals of economically developed and underdeveloped areas.

\begin{tabular}{|c|c|c|c|c|c|c|}
\hline \multirow[b]{2}{*}{ Parameters } & \multicolumn{2}{|c|}{ Day 1} & \multicolumn{2}{|c|}{ Day 3} & \multicolumn{2}{|c|}{ Day 7} \\
\hline & DH & $\mathrm{UH}$ & DH & UH & DH & $\mathrm{UH}$ \\
\hline $\begin{array}{l}\mathrm{FiO}_{2} \\
\text { No. of cases }\end{array}$ & $\begin{array}{c}46.2(19) \\
214\end{array}$ & $\begin{array}{l}44.8(14) \\
161\end{array}$ & $\begin{array}{l}39(14) \\
143\end{array}$ & $\begin{array}{l}39.2(14) \\
99\end{array}$ & $\begin{array}{c}39(24) \\
67\end{array}$ & $\begin{array}{c}39.2(9) \\
49\end{array}$ \\
\hline $\begin{array}{l}\mathrm{PIP}\left(\mathrm{cm} \mathrm{H}_{2} \mathrm{O}\right) \\
\text { No. of cases }\end{array}$ & $\begin{array}{l}26(9)^{\mathrm{a}} \\
146\end{array}$ & $\begin{array}{l}27(8) \\
113\end{array}$ & $\begin{array}{c}25.4(9.3) \\
102\end{array}$ & $\begin{array}{l}26(9) \\
89\end{array}$ & $\begin{array}{c}24.2(4.5) \\
57\end{array}$ & $\begin{array}{c}28.6(10) \\
39\end{array}$ \\
\hline $\begin{array}{l}\mathrm{MAP}\left(\mathrm{cm} \mathrm{H}_{2} \mathrm{O}\right) \\
\text { No. of cases }\end{array}$ & $\begin{array}{l}12.5(6) \\
130\end{array}$ & $\begin{array}{l}11.9(3.0) \\
108\end{array}$ & $\begin{array}{c}10.8(7.3) \\
99\end{array}$ & $\begin{array}{l}10.9(4.4) \\
85\end{array}$ & $\begin{array}{l}11(6.6) \\
45\end{array}$ & $\begin{array}{c}10.9(5.5) \\
34\end{array}$ \\
\hline $\begin{array}{l}\text { Vte }(\mathrm{ml} / \mathrm{kg}) \\
\text { No. of cases }\end{array}$ & $\begin{array}{l}7.9(3.5)^{\mathrm{a}} \\
99\end{array}$ & $\begin{array}{l}9.0(3.9) \\
106\end{array}$ & $\begin{array}{l}7.9(3.8) \\
68\end{array}$ & $\begin{array}{l}8.5(4.3) \\
55\end{array}$ & $\begin{array}{c}8.6(3.2) \\
39\end{array}$ & $\begin{array}{l}9.1(5.7) \\
23\end{array}$ \\
\hline $\begin{array}{l}\mathrm{PEEP}\left(\mathrm{cm} \mathrm{H}_{2} \mathrm{O}\right) \\
\text { No. of cases }\end{array}$ & $\begin{array}{l}4.5(2)^{\mathrm{a}} \\
162\end{array}$ & $\begin{array}{l}4.5(2) \\
138\end{array}$ & $\begin{array}{l}4.2(2) \\
115\end{array}$ & $\begin{array}{l}4.5(2) \\
80\end{array}$ & $\begin{array}{c}4.2(2) \\
59\end{array}$ & $\begin{array}{l}4.5(2) \\
37\end{array}$ \\
\hline $\begin{array}{l}\text { RR } \\
\text { No. of cases }\end{array}$ & $\begin{array}{l}29(11) \\
152\end{array}$ & $\begin{array}{l}30(13) \\
112\end{array}$ & $\begin{array}{l}29(10) \\
119\end{array}$ & $\begin{array}{l}30(12) \\
71\end{array}$ & $\begin{array}{c}30(11) \\
29\end{array}$ & $\begin{array}{l}31(14) \\
40\end{array}$ \\
\hline MV (1/min) & $2.5(2.8)$ & $2.6(2.9)$ & $2.6(2.3)$ & $2.4(2.6)$ & $2.1(1.3)$ & $2.9(3.3)$ \\
\hline No. of cases & 108 & 97 & 82 & 63 & 45 & 30 \\
\hline
\end{tabular}

$\mathrm{DH}$, hospitals of developed areas; $\mathrm{UH}$, hospitals of less developed areas. Comparisons of the two groups, ${ }^{\mathrm{a}} \mathrm{P}<0.05$. FiO $\mathrm{O}_{2}$, fraction of inspire $\mathrm{O}_{2}$; PIP, peak inspiratory pressure; MAP, mean airway pressure; Vte, exhaled tidal volume; PEEP, positive end-expiratory pressure; RR, ventilation frequency; MV, minute ventilation.

Table VI. Comparison of mechanical ventilation parameters on the first, third and seventh day after admission of patients to university-affiliated hospitals and non-affiliated hospitals.

\begin{tabular}{|c|c|c|c|c|c|c|}
\hline \multirow[b]{2}{*}{ Parameters } & \multicolumn{2}{|l|}{ Day 1} & \multicolumn{2}{|c|}{ Day 3} & \multicolumn{2}{|l|}{ Day 7} \\
\hline & $\begin{array}{c}\text { University-affiliated } \\
\text { hospitals }\end{array}$ & $\begin{array}{l}\text { Non-affiliated } \\
\text { hospitals }\end{array}$ & $\begin{array}{c}\text { University-affiliated } \\
\text { hospitals }\end{array}$ & $\begin{array}{l}\text { Non-affiliated } \\
\text { hospitals }\end{array}$ & $\begin{array}{l}\text { University-affiliated } \\
\text { hospitals }\end{array}$ & $\begin{array}{c}\text { Non-affiliated } \\
\text { hospitals }\end{array}$ \\
\hline $\mathrm{FiO}_{2}$ & 49 (19) & $44(14)$ & $43(10)$ & $39(14)$ & $43(20)$ & $39(14)$ \\
\hline No. of cases & 213 & 192 & 148 & 129 & 73 & 58 \\
\hline $\mathrm{PIP}\left(\mathrm{cm} \mathrm{H}_{2} \mathrm{O}\right)$ & $25.4(7.9)^{\mathrm{a}}$ & $24.2(8.4)$ & $23.5(6.7)^{\mathrm{a}}$ & $24.3(9.2)$ & $23.9(7.2)$ & $25.2(10.1)$ \\
\hline No. of cases & 150 & 134 & 105 & 93 & 49 & 56 \\
\hline $\mathrm{MAP}\left(\mathrm{cm} \mathrm{H}_{2} \mathrm{O}\right)$ & $13.4(6)$ & $11.0(3.2)$ & $11.9(7)$ & $10.1(4.0)$ & $12.8(7.5)$ & $10.5(5.1)$ \\
\hline No. of cases & 146 & 138 & 112 & 95 & 66 & 53 \\
\hline Vte $(\mathrm{ml} / \mathrm{Kg})$ & $8.4(3.9)^{\mathrm{a}}$ & $8.7(3.3)$ & $8.5(4.2)$ & $7.6(3.7)$ & $8.9(3.7)$ & $7.2(4.2)$ \\
\hline No. of cases & 109 & 88 & 79 & 53 & 33 & 20 \\
\hline $\operatorname{PEEP}\left(\mathrm{cm} \mathrm{H}_{2} \mathrm{O}\right)$ & $5(4)^{\mathrm{a}}$ & $4(2)$ & $5(4)$ & $4(2)$ & $5(3)$ & $4(2)$ \\
\hline No. of cases & 168 & 151 & 121 & 106 & 64 & 53 \\
\hline RR & $29(13)$ & $31(11)$ & $29(12.6)$ & $34(11)$ & $34(10.8)$ & $31(13)$ \\
\hline No. of cases & 166 & 125 & 137 & 104 & 75 & 53 \\
\hline MV (1/min) & $2.6(3.1)$ & $2.3(2.7)$ & $2.4(2.2)$ & $2.3(2.0)$ & $2.1(1.7)$ & $2.8(2.5)$ \\
\hline No. of cases & 123 & 101 & 89 & 68 & 34 & 37 \\
\hline
\end{tabular}

Comparisons of the two groups. $\mathrm{P}<0.01$ and ${ }^{\mathrm{a}} \mathrm{P}<0.05$. Numbers are the median value, numbers in brackets represent interquartile ranges, which were equal to the difference of upper quartiles and lower quartiles. $\mathrm{FiO}_{2}$, fraction of inspire $\mathrm{O}_{2}$; PIP, peak inspiratory pressure; MAP, mean airway pressure; Vte, exhaled tidal volume; PEEP, positive end-expiratory pressure; RR, ventilation frequency; MV, minute ventilation.

Data from the study have shown that cases of AHRF were primarily concentrated in the preschool age groups $(<1$ year, 57.1 vs. $42.9 \%$; <2 years, 66.7 vs. $33.3 \%$ ), which was similar to the age spectrum previously observed (13). The disease spectrum of this age group was simpler than that of the 6-year group, which was more suitable for the study of small tidal volume ventilation. The comparison between the AHRF respiratory supported treatment of our study and that of the 2006 study showed that PEEP (5 vs. $4 \mathrm{~cm} \mathrm{H}_{2} \mathrm{O}, \mathrm{P}=0.018$ ), $\mathrm{FiO}_{2}$ (0.5 vs. $\left.0.4, \mathrm{P}<0.001\right), \mathrm{PaO}_{2}$ (70 vs. $60 \mathrm{mmHg}, \mathrm{P}<0.001$ ), and PIP (20 vs. $24 \mathrm{~cm} \mathrm{H}_{2} \mathrm{O}, \mathrm{P}<0.001$ ), were all statistically different. In the present study, the conditions of PIP and PEEP 
when included, were more suitable for the requirements of low tidal volume ventilation than those in 2006. The current study therefore provided strong evidence for the safety and effectiveness of respiratory support in the PICU through a lung-protective, small tidal volume ventilation strategy, which was also confirmed in adult patients with $\operatorname{ARDS}(18,19)$. Therefore, the lung-protective, small tidal volume ventilation strategy (20) should be gradually used by PICU physicians.

The occurrence rates of AHRF and ARDS, and the proportion of mechanical ventilation used in patients of non-university-affiliated hospitals were higher than those of university-affiliated hospitals. In addition, the mortality rates and rates of abandonment of non-affiliated hospitals were higher than those of university-affiliated hospitals, while the higher LIS and OI, and relatively lower $\mathrm{PaO}_{2} / \mathrm{FiO}_{2}$ ratio of the included critical patients indicated that the critical degree of patients in university-affiliated hospitals was higher than that in non-affiliated hospitals. From the comparison of specific respiratory parameters, it was found that Vte of patients in university-affiliated hospitals was higher than that of patients in non-affiliated hospitals. PEEP, PIP and MAP, which were applied in patients in university-affiliated hospitals, were higher than those in non-affiliated hospitals, which indicated that because of the influence of academic background, respiratory support levels and diagnosis plans of university-affiliated hospitals were higher than those of non-affiliated hospitals. The patient in university-affiliated hospitals also had better compliance when participated in multicenter clinical studies (21). Therefore, improving the quality of respiratory therapy is useful to improve the prognosis of patients, suggesting that in the popularization of respiratory support (22), attention should be given to improving technology and training of PICU medical teams.

In conclusion, the levels of economic development and academic background of hospitals are important factors affecting the prognosis of patients with AHRF. There are significant differences in the prognosis of critical patients in the PICU, and in respiratory support for AHRF in different regions and various hospitals in China. However, with the development of economic level and medical exchange, the gap between units in China is shrinking. Subsequent clinical studies should focus on the assessment of security and effectiveness of differences in tidal volume ventilation for the treatment of AHRF (23). Except for Vte, more attention should be given to the significance of setup parameters of PIP and PEEP for the prognosis of AHRF.

\section{References}

1. Yu WL, Lu ZJ, Wang Y, Shi LP, Kuang FW, Qian SY, Zeng QY, Xie MH, Zhang GY, Zhuang DY, et al; Collaborative Study Group of Pediatric Respiratory Failure: The epidemiology of acute respiratory distress syndrome in pediatric intensive care units in China. Intensive Care Med 35: 136-143, 2009.

2. Hu X, Qian S, Xu F, Huang B, Zhou D, Wang Y, Li C, Fan X, Lu Z and Sun B; Chinese Collaborative Study Group for Pediatric Respiratory Failure: Incidence, management and mortality of acute hypoxemic respiratory failure and acute respiratory distress syndrome from a prospective study of Chinese paediatric intensive care network. Acta Paediatr 99: 715-721, 2010.

3. Flori HR, Glidden DV, Rutherford GW and Matthay MA: Pediatric acute lung injury: prospective evaluation of risk factors associated with mortality. Am J Respir Crit Care Med 171: 995-1001, 2005.
4. Timmons OD, Dean JM and Vernon DD: Mortality rates and prognostic variables in children with adult respiratory distress syndrome. J Pediatr 119: 896-899, 1991.

5. Goh AY, Chan PW, Lum LC and Roziah M: Incidence of acute respiratory distress syndrome: a comparison of two definitions. Arch Dis Child 79: 256-259, 1998.

6. Khemani RG, Conti D, Alonzo TA, Bart RD III and Newth CJ: Effect of tidal volume in children with acute hypoxemic respiratory failure. Intensive Care Med 35: 1428-1437, 2009.

7. Randolph AG, Meert KL, O'Neil ME, Hanson JH, Luckett PM, Arnold JH, Gedeit RG, Cox PN, Roberts JS, Venkataraman ST, et al; Pediatric Acute Lung Injury and Sepsis Investigators Network: The feasibility of conducting clinical trials in infants and children with acute respiratory failure. Am J Respir Crit Care Med 167: 1334-1340, 2003.

8. Brochard L, Lefebvre JC, Cordioli RL, Akoumianaki E and Richard JC: Noninvasive ventilation for patients with hypoxemic acute respiratory failure. Semin Respir Crit Care Med 35: 492-500, 2014.

9. MacIntyre NR: Supporting oxygenation in acute respiratory failure. Respir Care 58: 142-150, 2013.

10. Li Y, Wang Q, Chen H, Gao HM, Zhou T and Qian SY: Epidemiological features and risk factor analysis of children with acute lung injury. World J Pediatr 8: 43-46, 2012.

11. Pollack MM, Ruttimann UE and Getson PR: Pediatric risk of mortality (PRISM) score. Crit Care Med 16: 1110-1116, 1988.

12. No authors listed: Guidelines for developing admission and discharge policies for the pediatric intensive care unit. Pediatric Section Task Force on Admission and Discharge Criteria, Society of Critical Care Medicine in conjunction with the American College of Critical Care Medicine and the Committee on Hospital Care of the American Academy of Pediatrics. Crit Care Med 27: 843-845, 1999.

13. Bernard GR, Artigas A, Brigham KL, Carlet J, Falke K, Hudson L, Lamy M, LeGall JR, Morris A and Spragg R; The Consensus Committee: Report of the American-European consensus conference on ARDS: definitions, mechanisms, relevant outcomes and clinical trial coordination. Intensive Care Med 20: 225-232, 1994

14. Doyle RL, Szaflarski N, Modin GW, Wiener-Kronish JP and Matthay MA: Identification of patients with acute lung injury. Predictors of mortality. Am J Respir Crit Care Med 152: 1818-1824, 1995.

15. Kahn JM, Goss CH, Heagerty PJ, Kramer AA, O'Brien CR and Rubenfeld GD: Hospital volume and the outcomes of mechanical ventilation. N Engl J Med 355: 41-50, 2006.

16. Jordan García I, Arriourtúa AB, Torre JA, Antón JG, Vicente JC and González CT: A national multicentre study on nosocomial infections in PICU. An Pediatr (Barc) 80: 28-33, 2014 (In Spanish).

17. Cifra CL, Bembea MM, Fackler JC and Miller MR: The morbidity and mortality conference in PICUs in the United States: a national survey. Crit Care Med 42: 2252-2257, 2014.

18. Oba Y and Salzman GA: Ventilation with lower tidal volumes as compared with traditional tidal volumes for acute lung injury. N Engl J Med 343: 813-824, 2000.

19. Spieth PM, Güldner A, Huhle R, Beda A, Bluth T, Schreiter D, Ragaller M, Gottschlich B, Kiss T, Jaber S, et al: Short-term effects of noisy pressure support ventilation in patients with acute hypoxemic respiratory failure. Crit Care 17: R261, 2013.

20. Briel M, Meade M, Mercat A, Brower RG, Talmor D, Walter SD, Slutsky AS, Pullenayegum E, Zhou Q, Cook D, et al: Higher vs. lower positive end-expiratory pressure in patients with acute lung injury and acute respiratory distress syndrome: systematic review and meta-analysis. JAMA 303: 865-873, 2010.

21. De Luca D, Piastra M, Chidini G, Tissieres P, Calderini E, Essouri S, Medina Villanueva A, Vivanco Allende A, Pons-Odena M, Perez-Baena L, et al; Respiratory Section of the European Society for Pediatric Neonatal Intensive Care (ESPNIC): The use of the Berlin definition for acute respiratory distress syndrome during infancy and early childhood: multicenter evaluation and expert consensus. Intensive Care Med 39: 2083-2091, 2013.

22. Marohn K and Panisello JM: Noninvasive ventilation in pediatric intensive care. Curr Opin Pediatr 25: 290-296, 2013.

23. Desai AR and Deep A: Ventilatory strategies and adjunctive therapy in ARDS. Indian J Pediatr 73: 661-668, 2006. 